ISSN 1112-9867

Available online at

http://www.jfas.info

\title{
EXPERIMENTAL INVESTIGATION OF FLOW PATTERN AROUND REPELLING AND ATTRACTING T-HEAD SPUR DIKES ON FLAT BED
}

\author{
A. Mahdieh NajafAbadi ${ }^{*}$ and M. M. Bateni \\ Department of Water Engineering, University of Urmia, Iran
}

Received: 24 April 2017 / Accepted: 26 August 2017 / Published online: 01 September 2017

\begin{abstract}
Use of T-head spur dikes is one of the common methods to control erosion of riverbanks. Nevertheless, setting spur dikes in the flow direction leads to modification of flow path and local scour in the site of the spur dike. In case of intensification, this can destruct the structure and the riverbank. Therefore, understanding its mechanism and characteristics are crucial. The main objective of this study is to investigate and compare the flow pattern around submerged attracting and repelling T-head spur dikes in a flat bed. The experimental Flume was a rectangular channel with bed width of $92 \mathrm{~cm}$, bank height of $60 \mathrm{~cm}$ and length of $8.7 \mathrm{~m}$. around spur dike at 24 cross sections, 16 profiles and 3 depths velocity was measured by 2-D electromagnetic velocimeter. The results showed that downflow in upstream of repelling spur dike is stronger than the downstream part and the Length of downstream circulation zone is larger in attracting spur dike.
\end{abstract}

Keywords: T-head spur dike; repelling spur dike; attracting spur dike; flat bed.

Author Correspondence, e-mail: a.mahdieh@outlook.com

doi: http://dx.doi.org/10.4314/jfas.v9i3.25

\section{INTRODUCTION}

One of methods applied to control erosion of riverbanks is use of spur dikes. Spur dikes are in different shapes and angles towards the upstream. Their geometrical shapes and angles 
influence the design efficiency of such structure, remarkably. Setting spur dikes in the flow's direction leads to modification of flow path and local scour at the spur dike site. In case of intensification, this can destruct the structure and riverbank. Therefore, understanding the mechanism and characteristics as well as investigating flow pattern and local scour around the spur dike are crucial.

Eliasi et al. examined the effect of the radius of channel bend to width ratio on the flow pattern around a T-shaped spur dike in three dimensions, numerically. FLOW-3D® software used to simulate flow pattern. The simulation was executed using volume control method to model free surface and RNG k- $\varepsilon$ turbulences and solve Navier-Stokes equations. They pointed up good agreement of numerical simulation with laboratory results for water level and velocity profiles [1]. Kuhnle et al. compared numerically simulated to laboratory flow pattern data around a submerged trapezoid spur dike in straight directed flume for flat and scoured bed using $C C H E 3 D{ }^{\circledR}$ software. They expressed that the numerical simulation is in good agreement with laboratory data except at downstream of the spur dike [2]. McCoy et al. examined the flow fields around and between two vertical spur dikes in an open straight directed channel. The results showed creation of numerous transient horseshoe vortices at the base and upstream of the spur dikes [3].

Since danger of destructing the banks of the stream is more significant in bends, more studies have been done concerning flow pattern around spur dikes in bends. Mousavi-Naeini et al. investigated the effect of the radius of the bend on the flow behavior and pattern around T-head spur dike located at the position of $45^{\circ}$ in a $90^{\circ}$ bend, for three different radiuses. Their results showed that the flow pattern formed around the spur dike consists of two counterclockwise upstream and downstream vortices. In addition, increasing the radius would result in increased length of separation zone and upstream vortices. Decreased width of separation zone would cause formation of larger reattachment zone and downstream vortex [4]. Vaghefi et al. investigated the flow pattern around a T-head spur dike in $90^{\circ}$ bend with fixed bed and varying bend radius and geometry of the spur dike [5]. In another study, Karami, et al. numerically investigated the flow pattern and scouring around the T-head spur dike in $90^{\circ}$ bend with a movable bed using the SSIIM software. The results showed that the minimum 
amount of scouring occurred for width/length ratio equals to 0.8 . The maximum depth of scour hole ranges between $1 / 29$ to $1 / 42$ times of the depth of flow at upstream [6].

Here, flow pattern around T-head spur dikes over a fixed bed in straight flume investigated and differences for the case of attracting and repelling T-head spur dikes discussed.

\section{EXPERIMENTAL}

In this study, a laboratory fixed-bed concrete flume with $0.92 \mathrm{~m}$ width and $0.6 \mathrm{~m}$ depth is used. Flume includes a straight direction path with a length of $8.7 \mathrm{~m}$ succeeded by a $90^{\circ}$ bend. Radius of the bend is three times of the flume width. Layout of the laboratory flume is illustrated in Figure $1.45^{\circ}$ angled attractive and repelling types of spur dikes, made of PVC with $1 \mathrm{~cm}$ thickness and width/length ratio of 0.5 , operating in submerging condition, are used. Ratio of effective length of the spur dikes to normal stream depth is 0.7 . The spur dikes are installed within the [first] straight part of the channel. To study variations of flow field around the spur dikes, a three-dimentinal gridding scheme is used. The gridding scheme is shown in plan and cross-sectional view in Figure 2. Flow velocity data acquired using a two-dimensional velocity meter at the grid points. Microsoft EXCEL® and Tecplot360® computer applications are used to organize the recorded data and visualize velocity field, respectively.

Based on the griding scheme, velocity data at 16 longitudinal sections, 24 cross sections and three depths $(0.6 \mathrm{y}, 0.3 \mathrm{y}$ and $0.8 \mathrm{y})$ and distance of $3,5,8,10,12,15,18,20,22.5,25,30,35$, $45,65,75,85 \mathrm{~cm}$ distant from the adjacent bank are taken. 


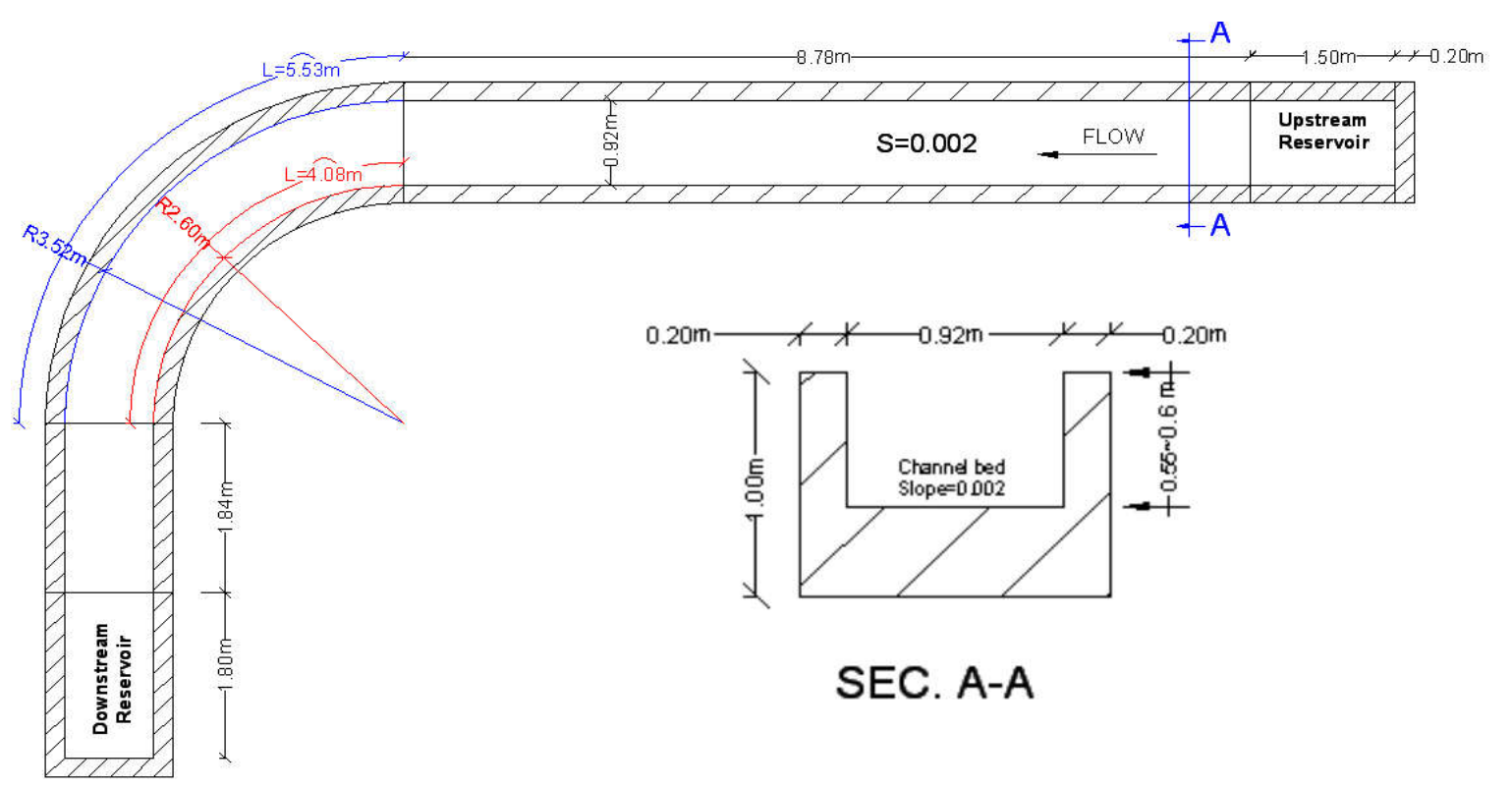

Fig.1. Plan and cross sectional view of the laboratory flume

(A)

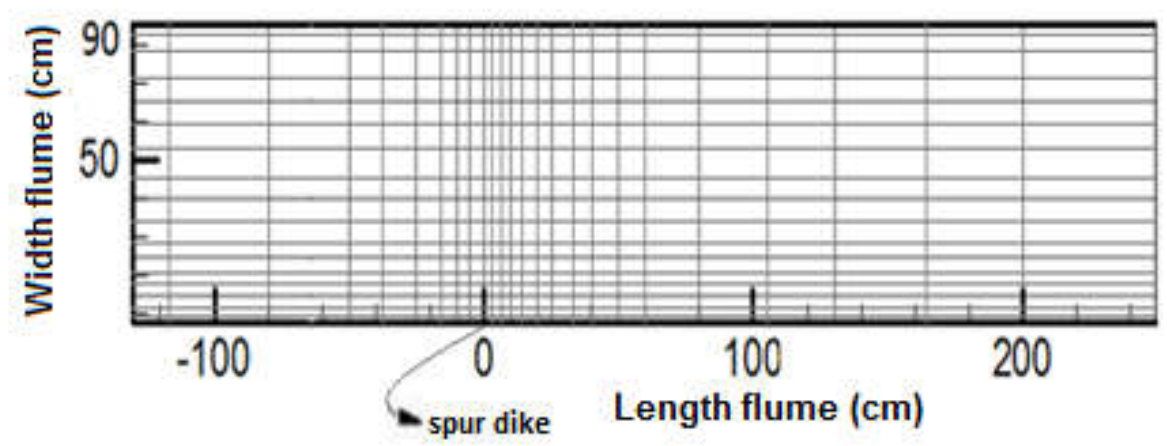

(B)

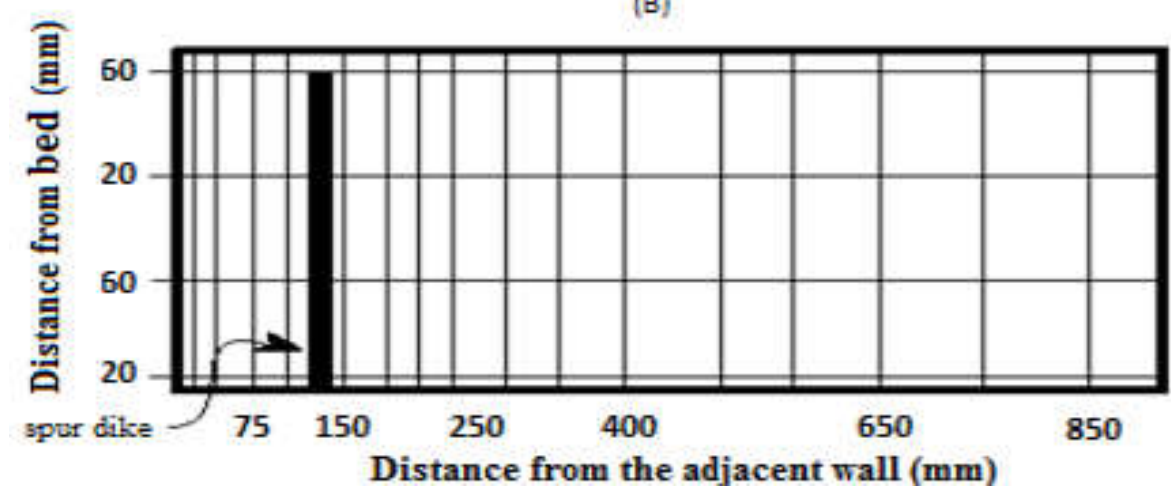

Fig.2. Gridding scheme adopted for velocity acquisition (A):plan view (B):cross sectional view.

\section{RESULTS AND DISCUSSION}

First, the observed velocity values describing the mechanism of flow around the T-head spur dikes are presented. In order to evaluate the bed shear stress, velocity data acquired at $0.1 \mathrm{y}$ above the bed are used. Moreover, differences of flow field around both repelling and 
attractive spur dikes are highlighted. Dimensionless parameters used for analysis and presenting results.

\subsection{Flow field pattern around T-head spur dike}

Flow velocity at upstream of the spur dike is maximum at inner layers. As seen in Figure 3(A), increased pressure due to sudden fall of velocity caused upflow and downflow in inner layers. The downflow and transverse component of vector velocity form horseshoe vortices at upstream and clockwise vortices in front of the spur dike, which may causes scoured materials to lift. In addition, longitudinal component of vector velocity may results in transfering materials to downstream. As illustrated in figure 3(B), flow field around the spur dikes can be separated into separation zone, shear layer, vortices zone, end point of vorticity zone and primary flow zone. In the figure, $b_{1}$ and $b_{2}$ denote the length of flow separation zone at upstream and downstream, respectively. In addition, $L$ and $h$ represent length of spur dike and maximum width of separation zone, respectively. Upstream velocity reduction, due to presence of the spur dikes, causes to form flow separation zone. Difference between velocity values in primary and secondary flows around the spurdikes causes formation of shear layer, which leads to formation of vorticity zone.

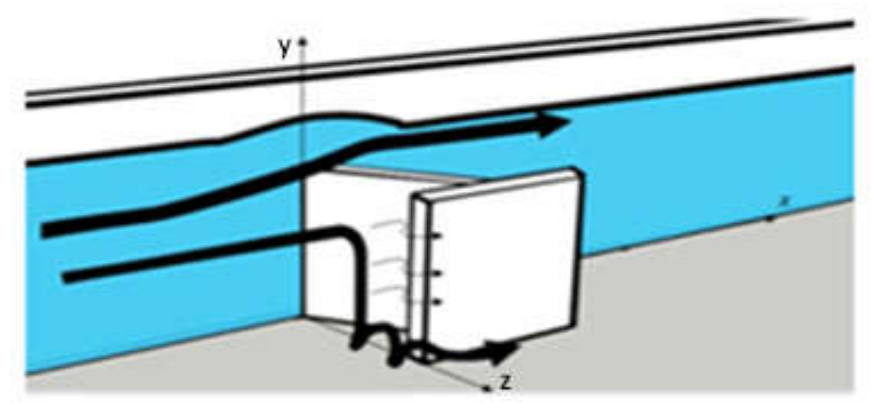

(a)

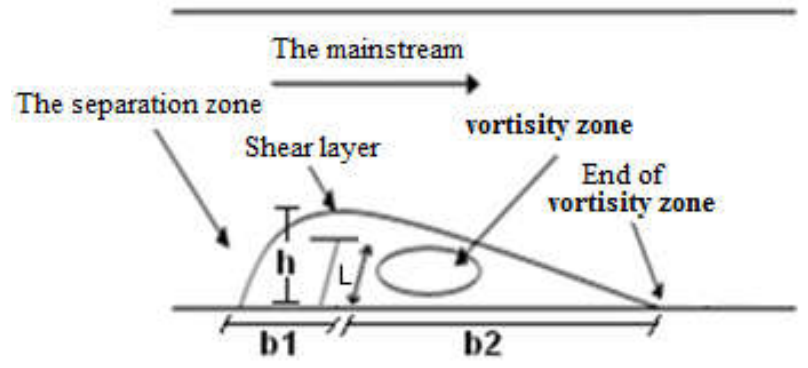

(b)

Fig.3. (a): Schematic view of flow mechanism at upstream (b): flow field classification around T-head spur dike. 
Figures 4 and 5 show plan view around the spur dikes at three levels of $0.3 \mathrm{y}, 0.6 \mathrm{y}$ and $0.8 \mathrm{y}$ from bed wheh y denotes normal depth of the stream. Flume contraction due to the spur dike and large width of separation zone cause an increase in flow velocity in front of the spur dike. Beginning point of separation zone for the repelling spur dike located more far upstream than what is for the attractive spur dike. On the other hand, length of separation zone at downstream for the attractive spur dike located more far upstream than what is for the repelling spur dike. Morever, separation zone is more expanded at higher levels. For example, for the case of attractive spur dike, at levels of $0.3 \mathrm{y}, 0.6 \mathrm{y}$ and $0.8 \mathrm{y}$ from bed, beginning of separation zone is at $0.6 \mathrm{~L}, 1.8 \mathrm{~L}$ and $3 \mathrm{~L}$ upstream, respectively. Length of sepration zone at downstream is $3.2 \mathrm{~L}, 1.7 \mathrm{~L}$ and $1.3 \mathrm{~L}$ at those levels. For the case of repelling spur dike, at levels of $0.3 \mathrm{y}, 0.6 \mathrm{y}$ and $0.8 \mathrm{y}$ from bed, beginning of separation zone is at $0.9 \mathrm{~L}, 1.2 \mathrm{~L}$ and about 1.2L upstream, respectively. Length of sepration zone at downstream is $2.3 \mathrm{~L}, 1.9 \mathrm{~L}$ and $1.5 \mathrm{~L}$ at those levels. In figure 6 and 7, the diagrams show variations of the separation length at upstream $\left(b_{1}\right)$ and downstream of the spur dike $\left(b_{2}\right)$ at various levels $\left(\mathrm{y}_{1}\right)$ for the both attractive and repelling spur dikes in terms of dimensionless parameters. 


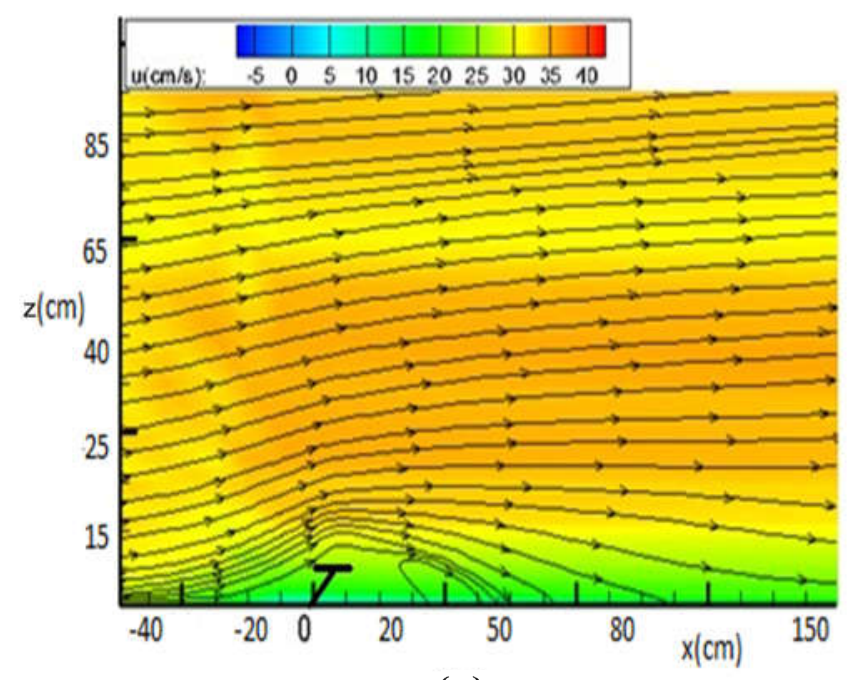

(a)

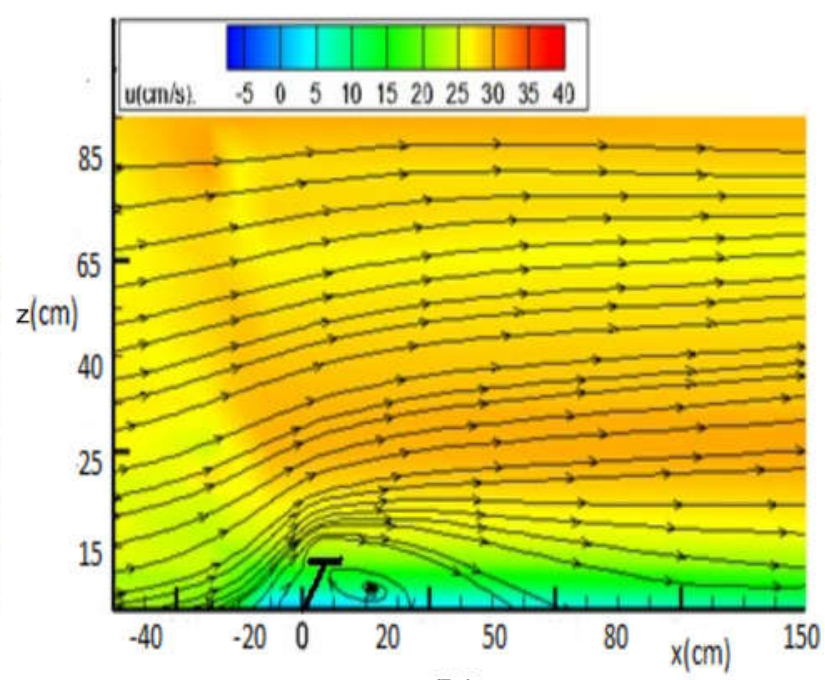

(b)

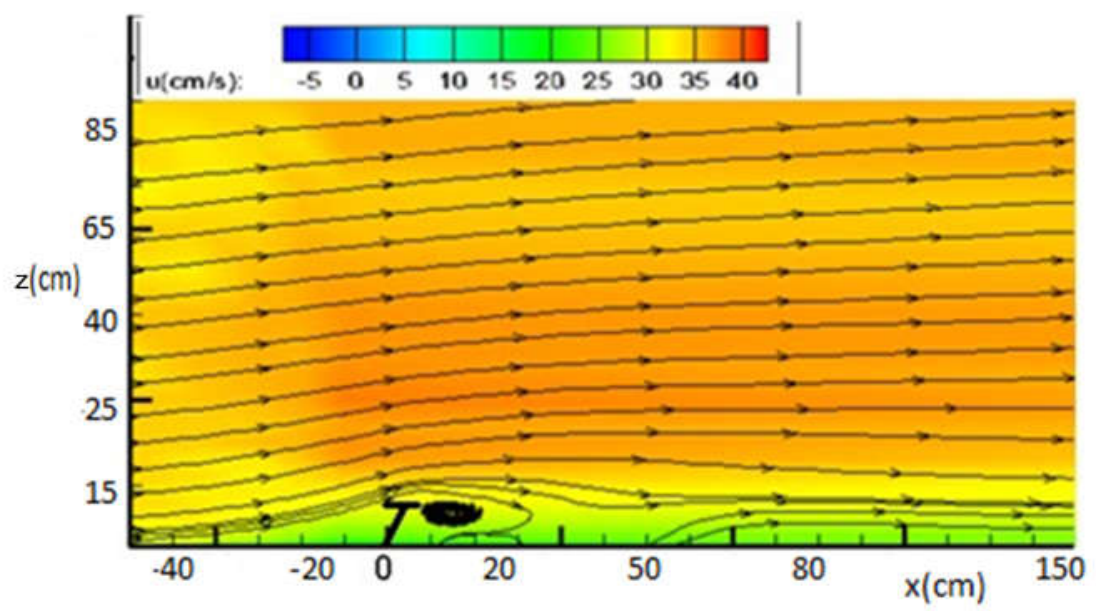

(c)

Fig.4. contour lines of the longitudinal component of velocity for attractive spur dike at three levels (a): 0.3y, (b): 0.6y and (c): $0.8 y$ from the bed. 


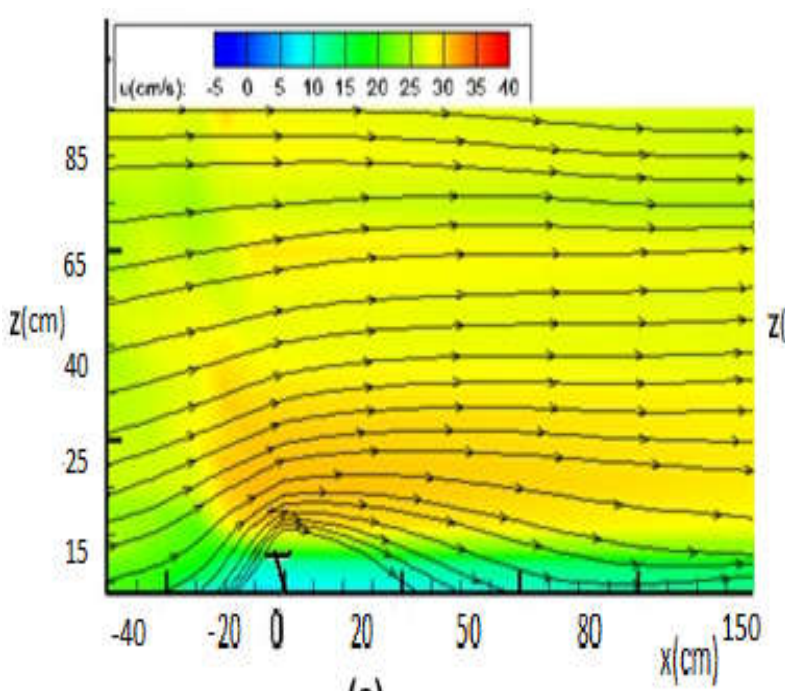

(a)

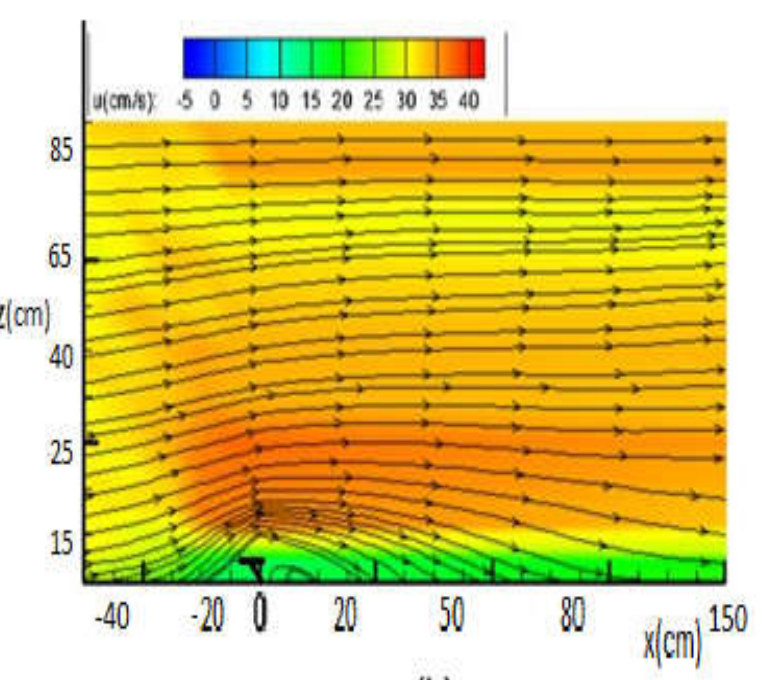

(b)

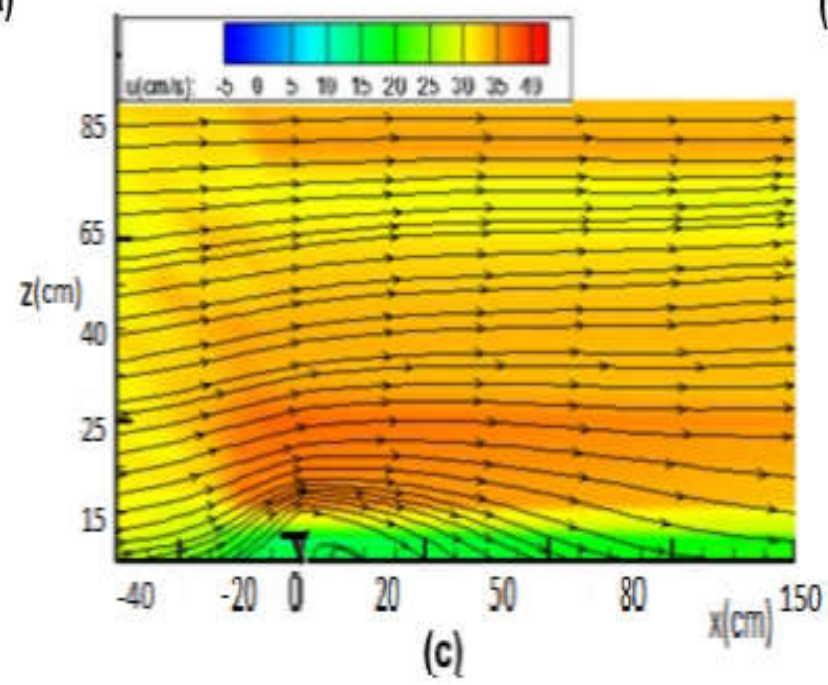

Fig.5. contour lines of the longitudinal component of velocity for repelling spur dike at three levels (a): 0.3y, (b): 0.6y and (c): 0.8y from the bed.

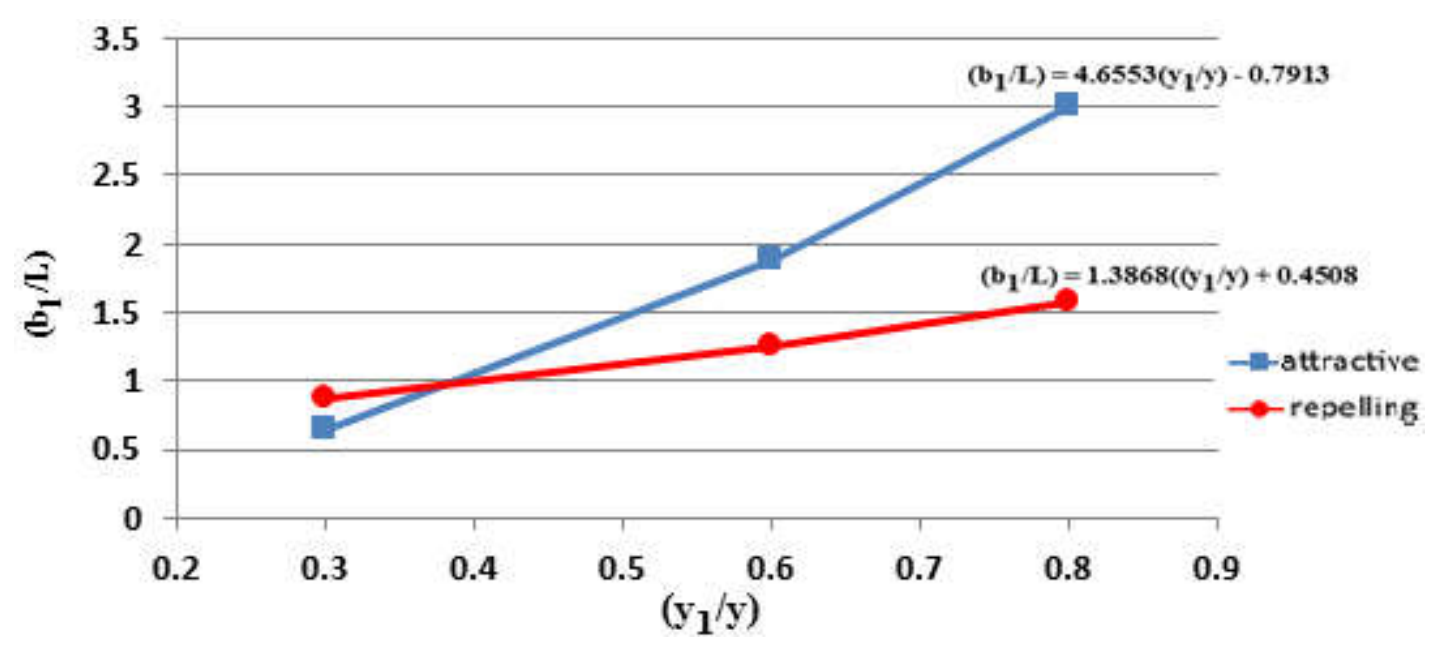

Fig.6. Dimensionless length of the separation zone, upstream of the spur dike versus diffrent water levels 


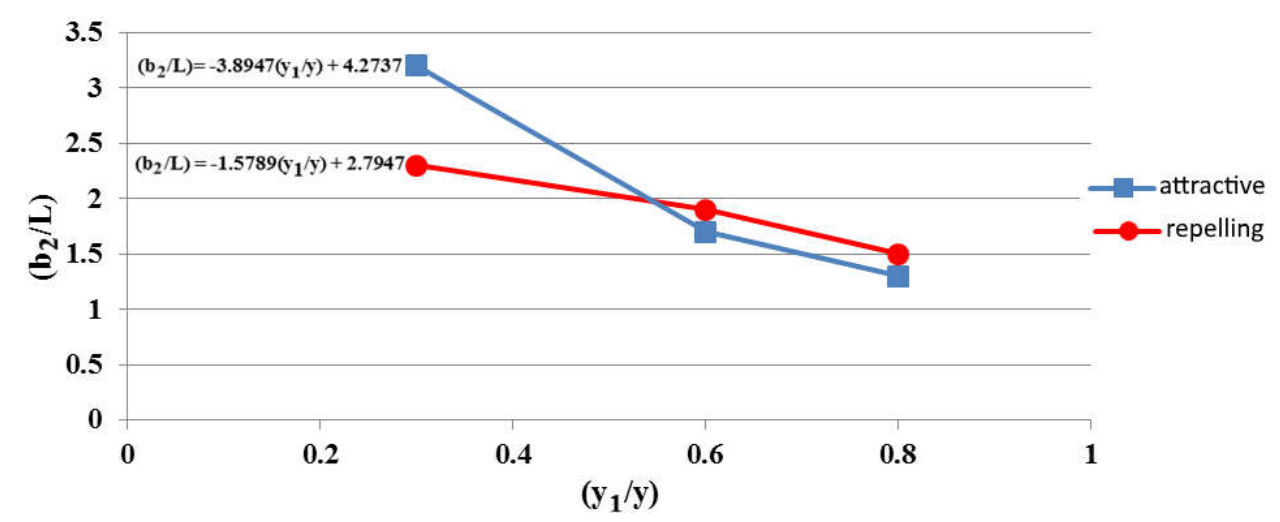

Fig.7. Dimensionless length of the separation zone, downstream of the spur dike versus diffrent water levels

Since maximum scour depth occured near the upstream wing of the spur dike, precise evaluation of the flow velocity at that point is crusial. Figure 8 shows contour lines of transverse component of velocity vector for the both attractive and repelling spur dikes. As seen in in this cross sectional view, transverse component of velocity is stronger for the attractive spur dike whereas maximum transverse velocity zone is wider for the repelling spur dike. It can be concluded that transverse component of the velocity maximized at the tip of the head for both types of spur dikes. Based on figure 8, maximum downflow velocity occured closer to the wall for the attractive spur dike. For case of the repelling spur dike, transverse component of maximum flow velocity in vicinity of the upstream wing is more developed along vertical direction. This phenomenon helps vertical component of pressure behind the repelling spur dike to reduce, which leads to less downflow velocity compared to the case of attractive spur dike.

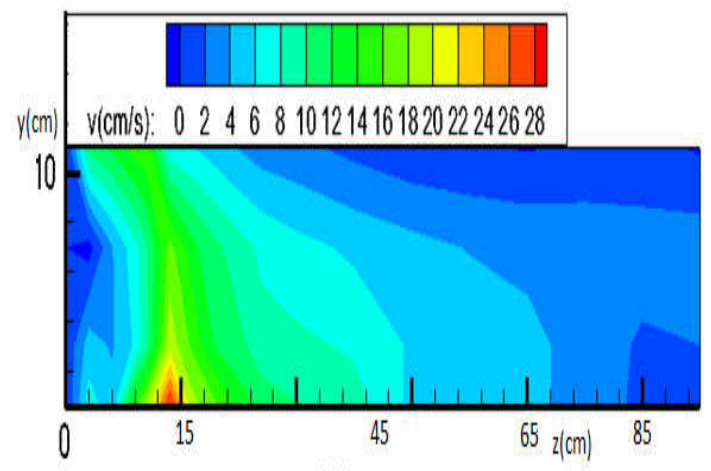

(a)

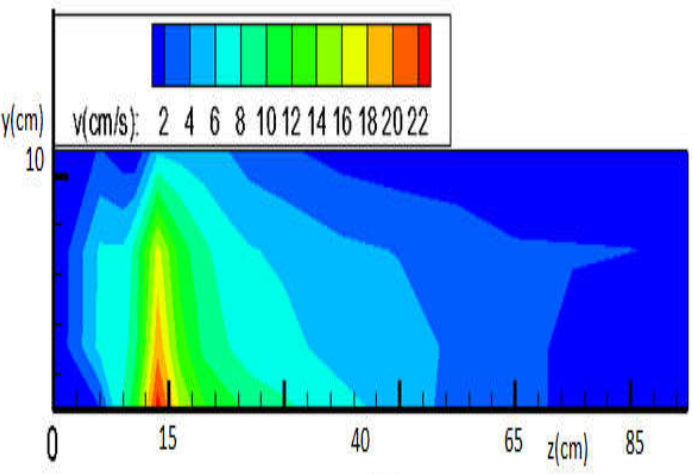

(b)

Fig.8. Contour lines of transverse component of velocity vector at cross-section of upper wing of (a): the repelling spur dike at $X=-25 \mathrm{~cm},(\mathrm{~b})$ : the attractive spur dike at $\mathrm{X}=0 \mathrm{~cm}$. 


\subsection{Bed Shear stresses}

Adopting equations from Dey and Barbahuiya [7], velocity data at depth of 0.1y from the bed are used in the following equations to obtain bed shear stress $\left(\tau_{b}\right)$ :

$\tau_{b}=\left(\tau_{x}^{2}+\tau_{z}^{2}\right)^{0.5}$

$\tau_{x}=\rho c_{f} \bar{u} \bar{w}$

$\tau_{z}=\rho c_{f} \bar{v} \bar{w}$

Where $\bar{u}$ and $\bar{v}$ are average velocities along the channel length and width, respectively. $\tau_{x}$ and $\tau_{z}$ are bed shear stresses along the channel length and width, respectively and $\rho$ indicates water density. In addition, $c_{f}$ is the coefficient of friction for smooth bed which can be calculated based on magnitude of the resultant velocity $(\bar{w})$. (Tingsanchali and Maheswaran 1990):

$c_{f=k^{2}\left(\ln E R c_{f}^{0.5 i}-1\right)^{-2}}$

$R=\frac{\pi \bar{w}}{v}$

$\bar{w}=\left(\bar{u}^{2}+\bar{v}^{2}\right)^{0.5}$

where $k$ is von Karman constant equals to $0.4, E$ is an empirical constant depends on the bed roughness which is equal to 9 for smooth bed. In addition, $R, v$ and $h$ indicate Reynolds number, kinematic viscosity of water and normal depth at upstream, respectively.

Plan view of dimentionless ratio of bed shear stress to upstream shear stress $\left(\tau_{b} \tau_{0}\right)$, is shown in Figure 9. Presence of the spur dikes caused bed shear stress to increase upto about nine times of the shear stress at upstream. However, the increase of shear stress is more significant for case of the repelling spur dike. 


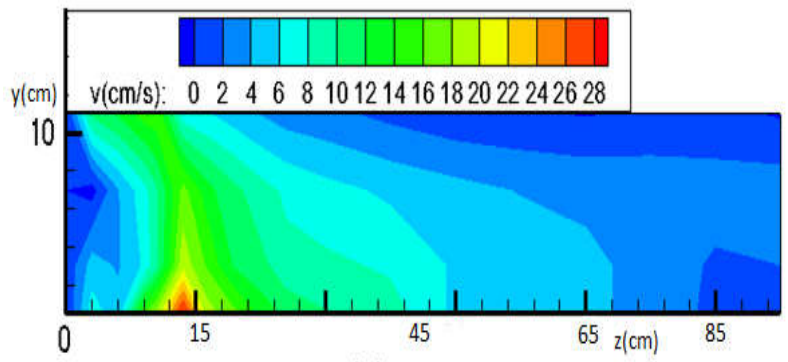

(a)

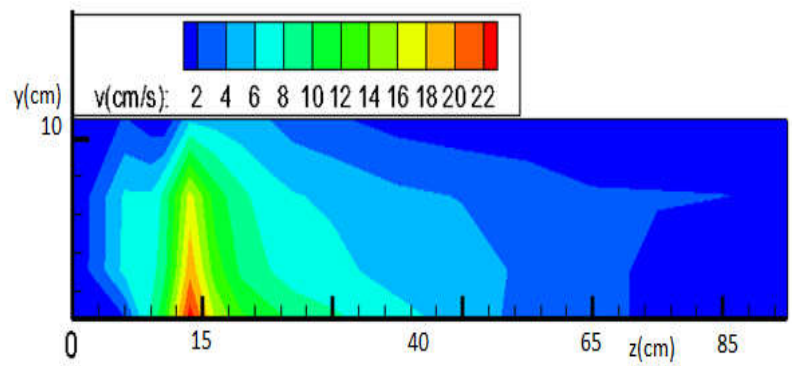

(b)

Fig.9. Dimensionless bed shear stress ( $0.1 \mathrm{y}$ from bed) for a) attractive b) repelling spur dike

\section{CONCLUSIONS}

In this study flow pattern around attracting and repelling T-head spur dikes over a fixed bed in straight flume investigated. The main results of the study can be summarized as follows:

1- Distancing from the bed, length of the separation zone at upstream of the spur dike is increasing for both two types of spur dikes.

2- The deviation of the flow toward the opposite bank at downstream of the spur dike for attractive one is more profound.

3- Downflow velocity and length of the separation zone are more significant for attractive spur dikes than what are for repelling ones.

4- Due to local contraction, Maximum longitudinal component of velocity vector occurred at tip of the spur dike.

5- Maximum shear stresses observed at the wing of the spur dikes. Increased shear stresses around the spur dike are due to increased flow velocity and turbulence.

\section{REFERENCES}

[1] Elyasi S, Akhtari A.A., and Seyedashraf O. A Numerical Study of the Effect of Submerged Groyne Shapes on Flow Pattern in Straight Open-Channels. Int. Bull. Water Res. and Dev., 2015, 3(1):72-80

[2] Kuhnle R.A., Yafei J., and Alonso C.V. J. Hydraul. Eng., 2008, 134 (7), 916-924, doi: 10.1061/(ASCE)0733-9429(2008)134:7(916)

[3] McCoy A., Constantinescu G., Weber L., Flow Turbul. Combust., 2006, 77 (1), 97-126, doi: 10.1007/s10494-006-9039-1 
[4] Mousavi-Naeini S.A., Vaghefi M., and Gghodsian M. Experimental Investigation of Relative Radius on Flow Pattern around at Shape Spur Dike in 90 Degree Bend with Rigid Bed. Water \& Wastewater, (2011): 15-23.

[5] Vaghefi M., Ghodsian M., and Salehi-Neyshabouri S.A.A. J. Hydraul. Eng., 2012, 138 (5), 471-474, doi: 10.1061/(ASCE)HY.1943-7900.0000536

[6] Karami H., Basser H., Ardeshir A., and Hosseini S.H. Water and Env. J., 2014, 28 (1), 1241-134, doi: 10.1111/wej.12019

[7] Dey S., Lambert M.F. J. Hydraul. Eng., 2005, 13 1(7), 610-614, doi : 10.1061/(ASCE)0733-9429(2005)131:7(610)

\section{How to cite this article:}

Mahdieh NajafAbadi A, Bateni MM. Experimental Investigation Of Flow Pattern Around Repelling And Attracting T-Head Spur Dikes On Flat Bed. J. Fundam. Appl. Sci., 2017, 9(3), 1644-1655. 